\title{
Optimization of reactive power consumption regimes by the electric centrifugal pumps installations
}

\author{
Vladimir Kopyrin ${ }^{1, *}$, Oleg Smirnov ${ }^{1}$, and Marina Deneko ${ }^{1}$ \\ ${ }^{1}$ Federal State Budget Educational Institution of Higher Education «Industrial University of \\ Tyumen», 625000 Tyumen, Russia
}

\begin{abstract}
The purpose of the article is to determine the optimal parameters inside the downhole compensator of the reactive power at which minimization consumption of active power is provided. The energysaving function for electric effect estimating with the use of the downhole compensator is propoused. Surfacing energy-saving functions are received.Their analysis showed that minimal consumption of the submerged motor reactive power is achieved by tre power of insidedownhole compensator 0.92 with the submersible motor power.
\end{abstract}

\section{Introduction}

The real share of hard-to-recover hydrocarbon reserves in Russia and in the world is increasing nowadays [1-3]. In view of it, the number of oil deposits with watercut increases from $30 \%$ to $50 \%$, some deposits have a watercut of $95 \%$ [4]. To maintain the planned volume of extracted oil-producing the oil companies increase the productivity of pumping plants.After this case, the power consumption of submersible electrical equipment is increasing.

Among the factors affecting improving the energy performance of oil production in the watercut changing, it is possible to emphasize the watercut liquid reduction [5-7] and compensation of power losses in elements of oil production installations $[8,9]$.

The watercut decreasing of extracted liquid is achieved by the quality improving of construction wells, water flooding systems and tamponing composition.

The increasing of efficient energy exertion in oil production is achived by energy efficient equipment with the highest efficiency [10, 11], the optimization in downhole equipment selection [12.13], the production process management [14], the quality of electricity improving [15], the hydraulic losses reduction by the pump-compensating pipes of maximum diameter using $[16,17]$.

The reduction of hydraulic losses by the pump- compressor pipes diameter increasing makes possible to reduce the active power consumption by the electric centrifugal pumps installations (ESP). Nevertheless, this method is not applying by most oil

\footnotetext{
${ }^{*}$ Corresponding author : kopyrinva@gmail.com
} 
producing companies as it is the high risk of the power cable damage and the reduction of the annular space.

The use of submersible asynchronous electric motors (SEM) with the increased voltage allows to rise the energy efficiency of oil production by reducing active power losses in the conductive elements of the electrical complex (ETC) ESP.This technical solution is mainly used for engines rated power up to $70 \mathrm{~kW}$ [8]. This is due to the fact that the increase in the nominal power of SEM leads to a "basic" rise in the nominal voltage, which is not always possible with use of existing windings insulating materials. The problem of rising the "basic" nominal voltage remains relevant for submersible electric motors with nominal power over $70 \mathrm{~kW}$.

At the operation of electric centrifugal pump installations at high-rate wells (flow rate above $150 \mathrm{~m} 3$ / day) the consumed active power of the SEM can reach $200 \mathrm{~kW}$ or more, and operating currents vary from 50 A to 130 A $[10,13]$. When the ESP operates, the power factor lies within the range 0.7-0.85 at the nominal load and can be reduced to 0.50.7 with underloads. The power factor is determined mainly by the power factor of the SEM. During the operation, the actual power factor of the submersible asynchronous electric motors is lower than the nominal value. This is due to the fact,that selected equipment works in non-optimal working areas.

Developed technical devices for reactive power compensation can be installed only on the surface. Nevertheless, this solution does not allow to compensate reactive power in ESP power cables, the length of which can reach $3500 \mathrm{~m}$. This leads to increasing the cables cross-section and to the high losses of power in them up to $15 \%$.

The publication purpose is the consumption optimization of reactive power modes by the installation of electric centrifugal pumps and determining the optimum parameters of the reactive power downhole compensators.

\section{Materials and methods}

The considered electrotechnical complex ESP has a power source (tires of the complete transformer substation are $10 / 0.4 \mathrm{kV}$ ); control station, power transformer, cable line, submersible asynchronous electric motor and downhole reactive power compensator (DRPC).

The active power is $P_{i}$, consumed by the ESP. It is expended on useful work performance by submersible electric motor and loss in conductive elements of electrotechnical complex. It also depends on the power of submersible electric motor and reactive power of the compensating system:

$$
P_{i}=P_{m}+\sum \Delta P=P_{m}+\Delta P_{T}+\Delta P_{C L}+\Delta P_{m},
$$

where $P_{m}-$ is an active power consumed by the submerged electric motor; $\Delta P_{T}, \Delta P_{C L}, \Delta P_{m}-$ is the loss of active power in the transformer, cable line and submersible electric motor.

Taking into account the change in the installation location of the compensating device (inside the well), the function $E_{E}$, characterizing the energy-saving effect from the introduction of downhole compensator is proposed to be defined as the ratio of the received consumed active power $-P_{\text {new }}$ to planned $-P_{\text {planned }}$ : 


$$
E_{E}\left(P_{m} ; \cos \varphi_{c}\right)=1-\frac{P_{\text {new }}\left(P_{m} ; \cos \varphi_{c}\right)}{P_{\text {planned }}\left(P_{m} ; \cos \varphi_{c}\right)},
$$

where $\cos \varphi_{c}-$ is required circuit power factor.

The optimality criterion is formulated for solving the optimization problem. This criterion $P_{n e w} \rightarrow$ min reflects the minimization of the ESP consumed active power, with taking into account the loss of active power in the electrical technical complex, depending on the downhole compensator power factor.

In this study, the power range of the submerged electric motors is from $100 \mathrm{~kW}$ to 250 $\mathrm{kW}$.

The analysis of the ESP energy performance showed that the average value of the power factor submersible asynchronous electric motors is 0.735 in some oil companies installations. This circumstance is due to the fact that the average load factor of the SEM is 0.65 . Therefore, the power factor of the $S E M$ is $\cos \varphi_{m}=0.735$ for calculating the required DRPC power.

The losses of active power in the power transformer are determined by the expression:

$$
\Delta P_{T}=3 \cdot i_{T}^{2} \cdot\left(R_{1 T}+R_{2 T}^{\prime}\right)
$$

where $i_{T}$ - is the current, flowing through the transformer windings; $R_{1 T}, R_{2 T}^{\prime}-$ is an active and reduced active resistance of the primary and the secondary windings of the power transformer.

The equivalent active resistance of the power transformer are determined by the expression:

$$
R_{e q T}^{\prime}=R_{1 T}+R_{2 T}^{\prime}=\frac{\Delta P_{h c} \cdot U_{h \cdot n o m}^{2} \cdot 10^{3}}{S_{n o m}^{2}},
$$

where $\Delta P_{h c}$ - is a short-circuit losses, $\mathrm{kW} ; U_{h . n o m}$ - nominal voltage of the highest transformer stage, $\mathrm{kV} ; S_{n o m}$ - total transformer power, $\mathrm{kVA}$.

The cable line consists of a main power cable and an extension cable connected to it. Losses of the active power in the cable line are determined by the expression:

$$
\Delta P_{C L}=3 \cdot i_{C L}^{2} \cdot R_{C L}
$$

where $i_{C L}-$ is the current flowing by cable line; $R_{C L}$ - active resistance of the currentcarrying conductors in the cable line.

The active resistance of the current-carrying conductors in the cable lines is determined by the expression:

$$
R_{C L}=10^{3} \cdot \rho \cdot\left(\frac{l_{1}}{S_{1}}+\frac{l_{2}}{S_{2}}\right) \cdot[1+0.004 \cdot(T-20)]
$$


where $\rho$ - is the conductor resistivity at $20^{\circ} \mathrm{C}$, for copper $\rho=0.0172 \Omega \cdot \mathrm{mm}^{2} / \mathrm{m} ; l_{1}, l_{2}-$ is the length of the main cable and extension cable, respectively, $\mathrm{km} ; S_{1}, S_{2}$ - is the crosssection of the current-conducting core of the main cable and of the extension cable accordingly, $\mathrm{mm}^{2} ; \mathrm{T}$ - the temperature of the current-conducting cores of the cables, ${ }^{\circ} \mathrm{C}$.

The temperature of the most heated section of the cable line is assumed as the rated temperature of the current-conducting cable cores. If the cross-section of the currentconducting cores of the main cable and the extension cable is not differ more than by one order (for example, $16 \mathrm{~mm}^{2}$ and $10 \mathrm{~mm}^{2}$ ), then the active resistance of the cable line core is calculated as for the main cable.

The required power of the downhole compensator is proposed to determine by the expression:

$$
Q_{D R P C}=P_{m . n o m} \cdot\left(\sqrt{\frac{1}{\cos ^{2} \varphi_{m}}-1}-\sqrt{\frac{1}{\cos ^{2} \varphi_{c}}-1}\right)
$$

The limitation of the required network power factor $0.80 \leq \cos \varphi_{\mathrm{c}} \leq 1$ is propoused for optimal parameters determination of the reactive power downhole compensator.

\section{Results}

The submersible electric motor is supplied with the power from transformer brand TMPN250/3 in the analyzed electrtechnical complex ESP. Its passport data are given in Table 1.

Table 1. Technical characteristics of the transformer TMPN-250/3.

\begin{tabular}{|c|c|c|c|c|c|c|c|}
\hline \multirow{2}{*}{$\begin{array}{c}\text { Power } \\
\text { kVA }\end{array}$} & \multicolumn{2}{|c|}{$\begin{array}{c}\text { Stresses } \\
\text { combination, } \\
\mathrm{kV}\end{array}$} & \multirow{2}{*}{$\begin{array}{l}\text { Scheme and } \\
\text { group of } \\
\text { winding } \\
\text { connection }\end{array}$} & \multicolumn{2}{|c|}{ Loss, kVA } & \multirow{2}{*}{$\begin{array}{c}\text { Voltage s.c., } \\
\%\end{array}$} & \multirow{2}{*}{$\begin{array}{l}\text { No-load } \\
\text { current, } \\
\quad \%\end{array}$} \\
\hline & $\begin{array}{c}\text { High } \\
\text { voltage }\end{array}$ & $\begin{array}{c}\text { Low } \\
\text { voltage }\end{array}$ & & Idle & $\begin{array}{c}\text { Short } \\
\text { circuit }\end{array}$ & & \\
\hline 250 & 2.5 & 0.4 & $\mathrm{Yn} / \mathrm{Y}-0$ & 0.65 & 3.7 & 6.0 & 1.5 \\
\hline
\end{tabular}

The length of the cable lines of ESP suppling can be $3500 \mathrm{~m}$ and reservoir fluids temperatures about $150{ }^{\circ} \mathrm{C}$ because of nowadays increasing share of hard-to-recover hydrocarbon reserves. Therefore, to evaluate the effect of cable line length to the amount of energy-saving effect $E_{E}$, the cable length range is assumed to be $1500 \mathrm{~m}, 2000 \mathrm{~m}, 2500 \mathrm{~m}$, $3000 \mathrm{~m}, 3500 \mathrm{~m}$. The brand cable KPBP with copper cores was chosen as the power cable. The temperature of the reservoir fluid is assumed to be $70^{\circ} \mathrm{C}$. Surfaces of the energy saving functions $E_{E}$ are shown in Fig.1.

\section{Discussion}

The surface analysis (Fig.1) showed that the maximum value of the energy saving function $E_{E}$ is achieved with $\cos \varphi_{\mathrm{c}}=1$ for all changes of the submersible asynchronous electric motors power, the lengths and cross sections of cable lines. At $\cos \varphi_{\mathrm{c}}=1$ the optimum value of the reactive downhole compensator power is $0.92 \cdot P_{m . n o m}$ with the accepted average power factor SEM 0.735. For example, with ESP equipped by the submersible electric motor with a power of $200 \mathrm{~kW}$, by the cable line length of $2500 \mathrm{~m}$ with the conductor cross-section of $16 \mathrm{~mm}^{2}$ and the intersquitted power compensator of $184 \mathrm{kvar}$, the energy savings settlement parameter is $7.7 \%$. 


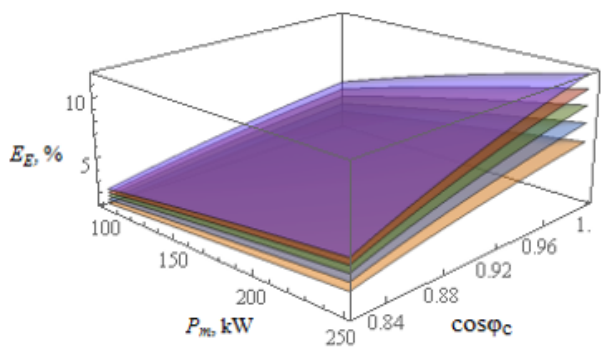

$\square 1.5 \mathrm{~km} \square 2.0 \mathrm{~km} \square 2.5 \mathrm{~km} \square 3.0 \mathrm{~km} \square 3.5 \mathrm{~km}$

a)

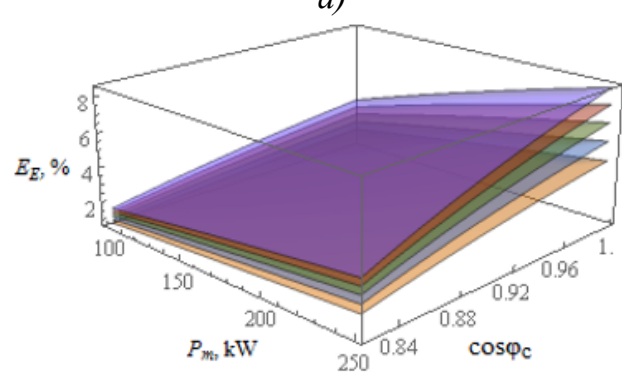

$1.5 \mathrm{~km} \square 2.0 \mathrm{~km} \square 2.5 \mathrm{~km} \square 3.0 \mathrm{~km} \square 3.5 \mathrm{~km}$

c)

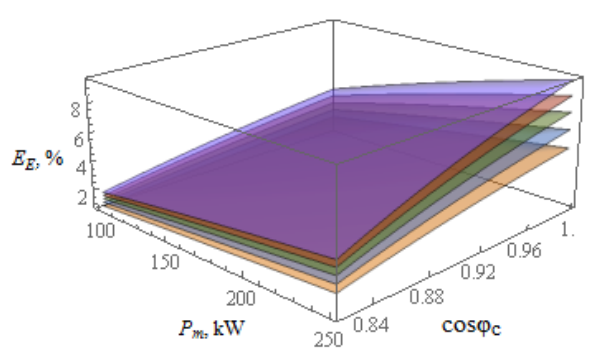

$\square 1.5 \mathrm{~km} \square 2.0 \mathrm{~km} \square 2.5 \mathrm{~km} \square 3.0 \mathrm{~km} \square 3.5 \mathrm{~km}$

b)

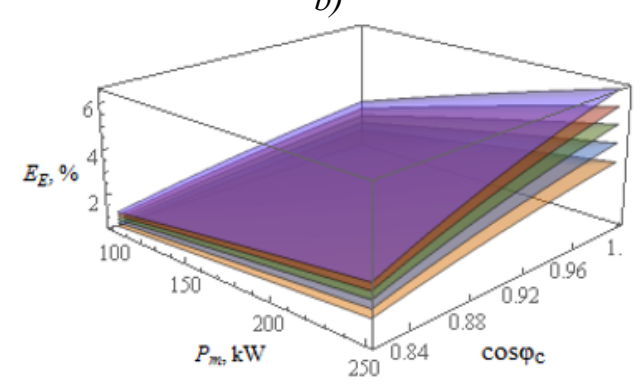

$\square 1.5 \mathrm{~km} \square 2.0 \mathrm{~km} \square 2.5 \mathrm{~km} \square 3.0 \mathrm{~km} \square 3.5 \mathrm{~km}$

d)

Fig. 1. Surfaces of the energy saving functions $E_{E}\left(P_{m} ; \cos \varphi_{c}\right)$ : a) $S_{C L}=16 \mathrm{~mm}^{2}$; b) $S_{C L}=21,5 \mathrm{~mm}^{2}$; c) $S_{C L}=25 \mathrm{~mm}^{2}$; d) $S_{C L}=35 \mathrm{~mm}^{2}$.

\section{Conclusions}

The optimum value of the downhole compensator reactive power is $0.92 \cdot$ Рд.ном with an average PED power factor of 0.735 . Estimated energy-saving effect ЭP with the reactive power downhole compensating varies from $1.4 \%$ to $11.8 \%$ depending on the capacity of the submersible electric motor, cable line length and its section.

\section{References}

1. V.G. Martynov, A.I. Ipatov, M.I. Kremenetsky, D.N. Gulyaev, V.M. Krichevsky, Development of geophysical and hydrodynamic monitoring on transition to the development of hard-to-recover oil reserves, Oil industry, No 3. pp. 106-109 (2014)

2. I.G. Yashchenko, Difficult extracted oil: physical and chemical properties and the ecological consequences of their extraction, Exposition of Oil and Gas, No I. pp. 3035 (2014)

3. O.V. Smirnov, A.E. Kozyaruk, K.V. Kuskov, A.L. Portnyagin, A.V. Safonov, Use of electroprocessing for increasing oil recovery, Izvestiya Vuzov. Oil and Gas, No 5. pp. 67-73 (2015)

4. F.S. Salimov, Involvement in the development of poorly drained, hard-to-recover oil reserves by changing directions of hydraulic fracturing, Exposition of Oil Gas, No 6. pp. 47-51 (2017) 
5. A.R. Habibbulin, Y.A. Lobkov, V.I. Dikov, Intellectual deposit of the company «Lukoil», Oil. Gas. Innovations. No 12. pp. 27-30 (2015)

6. A.V. Rodionov, Holding of GRP with preliminary injection of plugging compounds on oilfields of «LUKOIL - West Siberia» company, Engineering practice, No 9. pp. 74-78 (2015)

7. S.L. Obukhov, D.S. Kunaev, Flood management at the late stage of field development using the example of the northern site of the Izhevsk deposit, Engineering practice, No 7. pp. 4-8 (2016)

8. S.B. Yakimov, The high currents problem. Search of the optimal solutions, Engineering practice, No 3. pp. 14-19 (2016)

9. V.A. Novostruev, A comprehensive approach to energy efficiency in oil production ESP, Engineering practice, No 8. pp. 28-32 (2017)

10. S.B. Yakimov, M.N. Kaverin, V.P. Tarasov, On new perspectives of the SEM application with increased supply voltage for capital and equipment operating costs reducing, Equipment and technology for the oil and gas complex, No 4. pp. 34-38 (2015)

11. A.R. Khuzin, Estimation energy efficiency of submersible asynchronous and valve electric motors with increased voltage, Engineering practice, No 01-02. pp. 80-82 (2017)

12. A. Mahinya, Energy-efficient design system, Oil and Gas vertical, No 17-18. pp. 84-86 (2014)

13. V.P. Tarasov, S.V. Kuryaev, I.M. Golub, Use of specialized software for calculating energy consumption in a mechanized fund well, Engineering practice, No 3. pp. 22-26 (2016)

14. Z. Hiacong, Y. Jianxiong, J. Qingyue, W. Liguo, X. Dianguo, Research on intelligent power supply control based on sensor-less temperature identification of Electric Submersible Motor, 2015 9th International Conference on Power Electronics and ECCE Asia (ICPE-ECCE Asia) (Seoul, South Korea, 1-5 June 2015). DOI : 10.1109/ ICPE.2015.7168168

15. Ritchie Pragale, D.D. Ship, Investigation of premature ESP failures and oil field harmonic analysis, IEEE Transactions on Industry Applications. 2016. v. 53. Issue 3. pp. 3175-3181. DOI: 10.1109/ TIA.2016.2608958

16. A. S. Zuev, Energy efficiency improving in Open Society «OC «Rosneft». Goals and objectives, Engineering practice, No 3. pp. 4-9 (2016)

17. I.R. Baikov, M.I. Kuznetsova, S.V. Kitaev, Increasing the efficiency using equipment in the oil industry, Transport, oil products and hydrocarbons storage, No 2. pp. 18-20 (2013) 